\title{
Teacher support - an exploration of how foundation-phase teachers facilitate language skills
}

\author{
Anna-Marie Wium \\ Department Communication Pathology, University of Pretoria
}

Brenda Louw

Professor Emeritus: Department Communication Pathology, University of Pretoria

Correspondence to: A Wium (Anna-Marie1.Wium@ul.ac.za)

\begin{abstract}
The role of speech-language therapists (SLTs) has been redefined by White Paper 6, which emphasises the role of support to both teachers and learners. SLTs have expert knowledge and skills pertaining to communication and language, and therefore have much to contribute to the process of learning in teaching. This article builds on a previous article published in the 2010 edition of the journal, which reported on the process of supporting teachers to facilitate listening, language and numeracy skills in semi-rural and urban (township) contexts. In this follow-up article the focus is on the qualitative findings obtained from a specific section of the larger study. Where the overall study made use of a mixed methods approach to evaluate the process of providing support, and reported on the entire continued professional development (CPD) programme, this article focuses specifically on the qualitative data collected when the CPD programme addressed the facilitation of language. This article explores how the strategies were used in the classrooms, and the benefits of the support provided. The data discussed in this article were obtained from questionnaires, focus groups, and critical self-evaluation by teachers, as well as a research diary used by the programme facilitator. The results show that both the participants and their learners benefited from the support provided. The participants reportedly for the first time were able to meet curriculum outcomes which previously had been omitted, and showed an increased ability to plan their lessons. Several teachers experienced changes in their teaching practices and could reflect on their practices, which contributed to their professional development. These teachers became more empowered. Learning in the classroom was enhanced through increased participation of all learners, and enjoyment of the strategies.
\end{abstract}

Keywords: language, literacy, collaboration, numeracy, teachers, support, speech-language therapist

Speech-language therapists (SLTs) have expert knowledge and skills regarding language acquisition and literacy, which place them in a position to support teachers with the implementation of the Revised National Curriculum Statement (RNCS) (Department of Education, 2002). This article builds on a paper published in the 2010 edition of this journal (Wium, Louw \& Eloff, 2010) which focused on the development of a continued professional development (CPD) programme researched using a mixed methods approach. The focus was on the process of supporting teachers to facilitate listening, language and numeracy skills, whereas this article concentrates specifically on the language component of the overall study. This article explores how the teachers facilitated language skills in their classrooms as a result of strategies learnt in a CPD programme, and how they experienced the support provided. Such findings provide guidelines to SLTs who have to provide support to teachers in schools.

This article firstly discusses the collaborative roles of SLTs in education contexts and the interrelationship between listening, language and literacy. Such information was used to develop the workshop material to support teachers in the facilitation of language skills as described by the RNCS. The content of the CPD programme is briefly described in Appendix A.

\section{Background}

In South Africa the performance of learners in literacy and numeracy is alarmingly poor. The implication is that the majority of learners in South Africa are currently not receiving quality education, which can be considered as a violation of their constitutional rights. Attempts to facilitate literacy and numeracy learning, particularly in the early grades, need to be improved. Research by Girolametto, Weitzman, Lefebvre and Greenberg (2007) indicated that many teachers in care centres in the USA lack the knowledge to facilitate emergent literacy skills. Such findings may also apply to the South African context, as formal qualifications for teachers of grade $\mathrm{R}$ learners have not been a requirement until 2011 (Motshekga, 2010). The need for teacher support in the implementation of the curriculum has become a national priority (Department of Education, 2008; Motshekga, 2010), which
SLTs can provide by using a collaborative approach, particularly in the literacy learning area.

\section{Collaborative roles of the SLT in education contexts}

White Paper 6 (Department of Education, 2001) outlines the government's strategy to transform the current education system to make it more efficient, equitable and just. This document also specifies that SLTs should play consultative and collaborative roles in district and school-based support teams and support both teachers and learners who experience barriers to learning. White Paper 6 requires SLTs to provide training, mentoring, monitoring, and consultation to facilitate literacy and numeracy. With regard to literacy, teachers need to understand the complex nature of language and also how to facilitate it in the classroom.

The support of young learners who experience barriers to learning is essential because communication is central to the social, emotional, and academic development of young children (Department of Education, 2008). In terms of supporting learners SLTs should focus on the prevention of communication disorders (including literacy development problems), and provide language programmes in schools for the whole classroom as a group. Such preventive strategies are aligned with recommendations made by the American Speech and Hearing Association (ASHA) (2001), which require SLTs to provide foundation-phase learners (grades K - 3) with suitable intervention for literacy development and to address reading and writing skills in older learners.

Child language development is an interdisciplinary field of knowledge that is shared by teachers and SLTs because language is the foundation for developing competence in reading, writing, listening, and speaking. Language deficits may delay the acquisition of these four modes of communication, resulting in barriers to learning (Owens, 2004). Teachers and SLTs should work as a collaborative team to prevent and overcome such barriers, and to share their knowledge and skills to this effect. Teachers are primarily responsible for the teaching of reading and writing, whereas SLTs attend to the cross-modal literacy- 
language connection between all four modes of language, as these may affect one another. In South Africa many learners have to acquire oral and written language skills in their home language as well as English (Motshekga, 2010); this implies that learners who require support in the development of language will need to be supported in both their home language and in English.

\section{The inter-relationship between listening, language, literacy and numeracy}

Language is the foundation for learning (Owens, 2004), and is an integral part of 'literacy' in the foundation-phase curriculum (Motshekga, 2010). The four language systems shown in Table I are integrated in the RNCS as listening, speaking, reading, viewing, writing, thinking, and reasoning, as well as language structure and use (Department of Education, 2002). Each of these language systems is associated with either receptive or expressive modes of communication (Johnson \& Roseman, 2003).

\section{Table I. The four language systems that children} have to acquire

$\begin{array}{llll}\begin{array}{l}\text { Aural system } \\ \text { (language by } \\ \text { ear) }\end{array} & \begin{array}{l}\text { Oral system } \\ \text { (language by } \\ \text { mouth) }\end{array} & \begin{array}{l}\text { Print system } \\ \text { (language by } \\ \text { eye) }\end{array} & \begin{array}{l}\text { Written system } \\ \text { (language by } \\ \text { hand) }\end{array} \\ \begin{array}{l}\text { Receptive } \\ \text { language }\end{array} & \begin{array}{l}\text { Expressive } \\ \text { language } \\ \text { Spard words }\end{array} & \begin{array}{l}\text { Receptive } \\ \text { language } \\ \text { Printed words }\end{array} & \begin{array}{l}\text { Expressive } \\ \text { language } \\ \text { Written words }\end{array}\end{array}$

Language is not restricted to the oral modality, but also includes the visual modality (Johnson \& Roseman, 2003). Learners developing written language awareness discover that print is a highly organised system that reflects oral language and guides them to an understanding of the alphabetic principle (Justice \& Ezell, 2002), which relates to literacy in the RNCS.

\section{The National Curriculum: literacy}

In order for learners to develop language and communication skills (Department of Education, 2002), they firstly have to listen attentively and respond critically to information. The RNCS requires learners to communicate confidently and effectively in a spoken language in a wide range of situations. It is essential that learners learn to read and view information for enjoyment, and respond critically to the aesthetic, cultural and emotional values in texts. The RNCS requires learners to read and write different kinds of texts, but also to use language to think and reason. Learners are required to become competent in language structure and use and in doing so they have to use the sounds, words, and the grammar of a language to create and interpret texts. The development of language and communication skills is therefore critical for effective learning. Provided that the curriculum has been properly implemented, learners should be able to read and write and perform basic mathematical calculations by the end of grade 3 .

An outcomes-based education (OBE) approach is integral to the RNCS. It requires a skills-based, problem-solving, co-operative approach to teaching and learning. Teachers firstly have to decide on which skills and concepts they would like their learners to acquire, and then create suitable contexts in which such skills can be facilitated in the classroom. Within an OBE approach teachers plan in teams in order to equip learners with similar skills across the grade. Such group planning ensures that the standard of education is the same, and teachers need to agree on what to teach and the activities required (Department of Education, 2008). Learners from low socio-economic schools (SES) require a variety of experiences to facilitate the natural transition from oral language used at home to functional literate language used in school. Children living in poverty are at risk for learning disorders, and need support.

\section{The current context}

Education in South Africa is complex, as several challenges are encountered across contexts by both teachers and learners (Rembe, 2005). The poor performance of learners in South Africa can often be attributed to the fact that $40 \%$ of children in South Africa come from extremely impoverished backgrounds with limited access to learner support materials in their homes. Access to printed material in shared reading experiences, as well as parental beliefs about literacy, have been identified as having an effect on writing. Learners raised in poor communities mostly have limited exposure to printed material and subsequently may have very different attitudes to, and experiences of, the printed text from those of their peers (Nancollis, Lawrie, \& Dodd, 2005).

Locke, Ginsborg and Peers (2002) reported that preschool children who were raised in impoverished environments in the UK performed at lower levels in oral language assessments than the general population, which put them at risk for delayed written language skills. Learners from low SES often experience difficulty in making the shift from the language used at home to the abstract and decontextualised language used in the classroom (Justice \& Kaderavek, 2004). These learners may therefore require more support than their counterparts (Department of Education, 2008). Inadequate oral language development may result in poor academic performance (Figure 1), which points to a link between language and literacy.

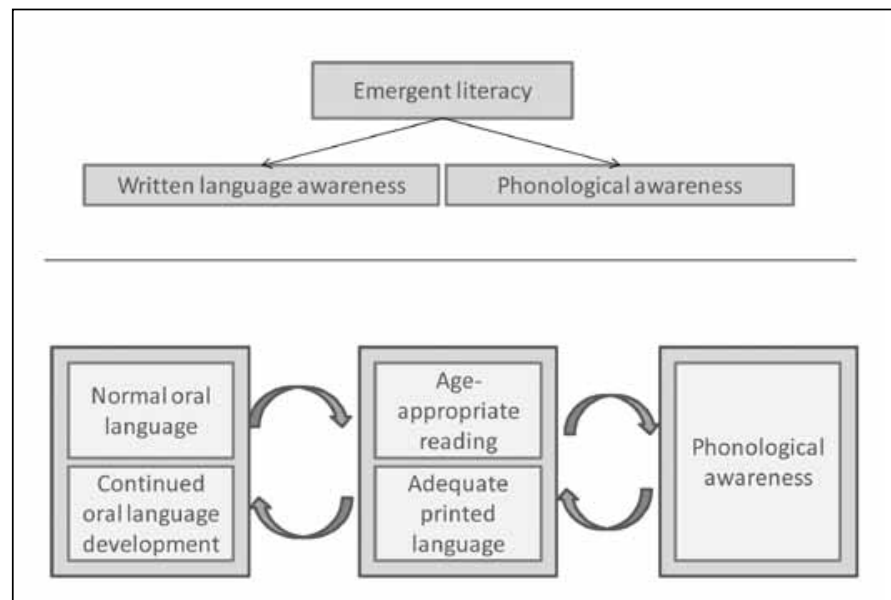

Fig. 1. The link between language and literacy development.

With reference to Figure 1, emergent literacy involves both written language awareness and phonological awareness (Justice \& Ezell, 2001), which in turn are based on normal oral language (particularly vocabulary development). In turn, age-appropriate oral language development is required for the development of reading competence, and therefore oral language proficiency is regarded as predictive of reading achievements as well as other written language achievements at a later stage.

Figure 1 shows that adequate print-related language (e.g. familiarity with books and visual symbols) is required for continued oral language development (Justice, Skibbe, \& Ezell, 2006). A similar reciprocal relationship exists between phonological awareness and reading, as each facilitates and is facilitated by the other (Justice, Skibbe \& Ezell, 2006). Learners' language learning is a crucial precursor to literacy. Poor literacy development contributes to later problems in language.

\section{The link between language and literacy}

Language is essential for the acquisition of literacy and numeracy because it is the foundation for speaking, reading, writing, and spelling. For emergent literacy to develop, learners need to firstly develop metalinguistic skills (Johnson \& Roseman, 2003) to identify and analyse specific sounds to allow them to read or write. Phonological development (including phonological awareness) (Figure 2) provides the bridge 
between language and literacy whereas higher-level phonological skills (e.g. sound manipulation and substitution) facilitate written language development in terms of reading and spelling (Johnson \& Roseman, 2003). Similarly, adequate language development is required to facilitate the language required for numeracy.

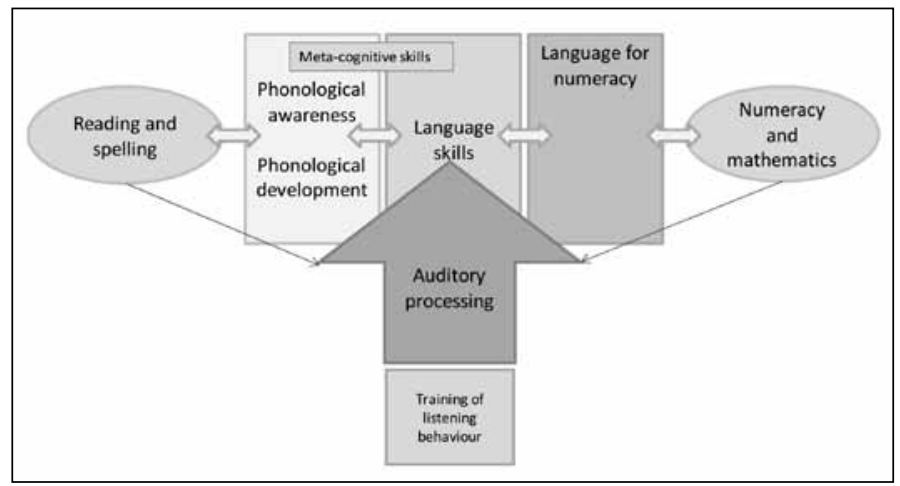

Fig. 2. The relationship between listening, language, literacy and numeracy.

The American Speech Hearing Association (ASHA)'s position statement (2001: 16) advocates that '.. . children need to experience reading, spelling, and writing for authentic communication purposes in which vocabulary, grammar, and discourse skills converge.'

Learners who do not have adequate and age-appropriate listening and language skills when entering formal education may be at risk for academic failure (Justice \& Kaderavek, 2004). This, in turn, may cause problems such as low self-esteem, social maladjustment, and inability to support themselves financially. It is therefore important to prevent academic failure by ensuring that learners acquire such skills as early as possible to allow them to become academically competitive when going to school.

Lessing and De Wit (2008) were of the opinion that the teachers' own lack of conceptual knowledge of language and the sub-skills required for literacy acquisition were at the root of their use of outdated teaching practices such as rote learning (e.g. drilling and chanting). Such outdated teaching practices do not facilitate learning. Teachers should aim instead for the development of meta-linguistic skills, which are required for learners to identify and analyse specific sounds to allow them to read or write (Johnson \& Roseman, 2003). It appears that learners from the most disadvantaged homes may be further challenged by the inadequate teaching practices prevalent in their classrooms. Teachers need to be supported to develop an understanding of the underlying concepts of language for learning, and to develop strategies and skills to facilitate the four language systems included in the RNCS in order for learners to develop literacy skills.

The specific CPD programme was part of a research study that covered several topics, and this particular article focuses on the language component of the entire research project. The topics were repeated in two contexts over a period of 2 years within an action research approach (Stringer, 2007). Such support was based on a three-pronged approach that consisted of a workshop (training component), the implementation of the skills in the classroom (practical component), and a mentoring component which provided the teachers with feedback on lesson plans and portfolio assignments (Wium, Louw, \& Eloff, 2010). The results obtained demonstrate how the facilitative strategies (e.g. the use of stories, songs, and art within a theme) were used to facilitate language. These activities were combined with reading and writing activities in the classroom, which were submitted as portfolios.

\section{Method}

\section{Aim of the research and objectives}

The aim of the research was to describe the outcomes of a particular CPD programme for foundation-phase teachers for the facilitation of language skills. To this end the research focused on how the participants (teachers) facilitated language development in their classrooms following the support provided, and how the participants valued the support provided to themselves and their learners.

In this article the term 'participant' refers to the teachers who participated in the research, and 'learners' to the learners in classrooms (grades R - 3).

\section{Study design}

An action research (Stringer, 2007) approach was used to determine how the participants facilitated language in their classrooms as a result of a specific CPD programme. This section of the research was originally included as part of the overall project that performed programme evaluation with mixed methods research (Wium, et al., 2010).

Each research cycle collected data with questionnaires prior to and following the workshops, which was followed by a period of practical implementation with the completion of portfolios. These portfolios displayed evidence of lesson planning and practical implementation of strategies in the classrooms, as well as self-reflection. At the conclusion of each cycle a focus group was conducted to evaluate the support provided, as well as the implementation of the strategies learnt. This research cycle was repeated in both contexts. Throughout each cycle the programme facilitator continually reflected on the entire process in a research diary.

\section{The context}

As mentioned in the previous article (Wium, et al., 2010), the research was repeated in two contexts: a semi-rural context and an urban (townships and informal settlements) context. Many learners in South Africa are educated in a language which is not their first language, or by teachers who speak a different language from the language of learning and teaching (LoLT) (Wium, 2010). The research was conducted in a context where Northern Sotho is the dominant language, which explains why $63 \%$ of the participants $(n=96)$ used this language as home language (L1). The other major languages represented as being the participants' L1 included Tswana (11\%), isiZulu (11\%), and to a lesser extent other official African languages of South Africa (excluding English and Afrikaans). Of the teachers $61 \%$ used Northern Sotho as the LoLT, whereas 33\% used English as LoLT in the semi-rural context compared with $25 \%$ in the urban township context. In both these contexts SeTswana and isiZulu were used as LoLTs to a lesser extent.

The CPD programme was presented in English as it is the language used for support by the Gauteng Department of Education (GDE), and also the language used in higher education (Ministry of Education, 2001). The aim of the CPD programme was to make the participants aware of the language skills required for learning, and to provide them with strategies to facilitate language development in the LoLT in relation to the RNCS.

\section{Participants}

The sampling process is discussed according to the criteria for selection, selection procedure and sample size.

\section{Criteria for section of the participants}

The selection of the schools to be supported was determined by the GDE as they aimed to redress past inequities. All participants included in this study were required to meet the following criteria:

- All had to be appointed full-time in teaching positions in the foundation phase (grades R, 1, 2 and 3) at schools in the targeted contexts.

- Only teachers who wanted to participate of their own free will were included. They were made aware that participation was voluntary and that they should not have been coerced by their superiors or peers. Those teachers who did not want to participate in the programme were excluded.

- Participants were expected to feel comfortable with the use of English as medium of instruction. An introductory letter of 
invitation to the schools alerted the teachers to the fact that the CPD programme would be provided in English, which allowed them to make informed decisions with regard to their participation in the research.

\section{Selection procedure}

Twelve schools from a semi-rural area and 12 schools from an urban/ densely populated area (including township schools and schools from informal settlements) were selected by the GDE. A total number of 24 low SES in the Tshwane region were targeted for this project over a period of 2 consecutive years.

- Each of the selected schools was required to identify one teacher from each grade level in the foundation phase who had volunteered to participate. The intention was for these participants to go back to their schools to share their knowledge and skills with the wider community.

- A similar procedure of volunteerism was used for compiling the focus groups. By using a nested design, the participants in the focus groups were already included in the original sample. Only one representative from each school was required to participate in the focus groups.

\section{Sample size}

Each grade level (grades R - 3) was represented by 12 participants, totalling 48 per annum. The entire sample consisted of 96 participants, which was considered sufficient to serve the purpose of this specific study and was representative of foundation-phase teachers in both contexts (Leedy \& Ormrod, 2010). As only one primary programme facilitator was available to conduct the workshops, a group of 48 participants per workshop was regarded as manageable. This number was considered sufficient to allow for possible attrition later in the programme. All the participants in the semi-rural context were female, whereas two of the participants in the urban context were male.

The focus groups each consisted of 12 participants (one representing each school per context), as this number is considered an adequate size for this purpose. It was also a representative sample (25\%) of the entire group that was trained, and allowed for attrition.

\section{Sampling method}

The sample was selected by means of stratified random sampling, which is a probability sampling method (Leedy \& Ormrod, 2010). Each participating school identified one individual from the list of volunteers in each grade level of the foundation phase (e.g. grades R, 1,2 , and 3 ), so that four participants from each school enrolled for the programme.

The qualitative strand obtained data from the entire sample (96) with questionnaires and portfolio assessments, but also used a nested design (Onwuegbuzie \& Dickinson, 2007) for the focus group. The participants who volunteered to participate in the focus groups originated from the entire sample and were therefore similar to those in the rest of the study. The sample was fairly homogeneous in terms of contexts, grade levels represented, and the teachers' experience in teaching, although not in terms of qualifications and language, and can therefore be considered as a cross-section of the population (Leedy \& Ormrod, 2010).

\section{Data collection methods}

The researchers wanted to understand how the participants implemented the strategies, as well as their impression of the benefits obtained from the support provided. This required various forms of qualitative data (Leedy \& Ormrod, 2010).

\section{Data collection material}

Data were obtained from open-ended questions via questionnaires, focus groups, critical reflection in portfolios, and a research diary completed by the researcher. Open-ended questions allowed respondents to express themselves freely and to make suggestions.
Although open-ended questions were useful to obtain additional information that could add to the understanding of phenomena, they were kept to a minimum as they take longer to complete and therefore could be a cause of non-response.

The questions, instructions and layout of the questionnaires were formulated based on guidelines obtained from the literature (McMillan \& Schumacher, 2010). A language editor reviewed and edited the questions, and two experts in the professional field, as well as a statistical advisor, scrutinised the various questionnaires to ascertain their validity as a measuring instrument, and to identify any potentially imprecise or ambiguous terms. Pretesting determined the clarity of instructions as well as questions, and the time for completion.

Focus groups were used to evaluate the workshop in terms of the participants' impressions/feelings about the workshop, and to obtain their experiences in implementing the strategies. In addition, information was obtained on how the participants regarded their own individual levels of skill in implementing the strategies at the end of the 3-week implementation period. The focus group schedule was compiled according to specific criteria obtained from the literature. Categories of questions included opening questions, introductory questions, transition questions, key questions, ending questions, and 'putting the parts together'.

The focus group plan was reviewed with experts and then pilot tested prior to use. Two experts in the professional fields of SLT and education scrutinised the schedules to assess the expected responses, which increased the likelihood of both content and construct validity. The portfolio assessments were used to evaluate the participants' applied knowledge and to monitor the implementation of strategies. It was assumed that implementation of the strategies learnt would increase the participants' competence in planning their lessons and facilitate language for learning.

The aim of the research diary was to document the research process and to reflect on issues arising. It provided insight regarding factors that could affect the outcomes of the programme. Data entries were used to share ideas on the process with experts and colleagues, but also to observe 'real world' processes. Questions could be answered about methods used. Such continued reflection resulted in changes being made; therefore this process could be associated with evidence-based research.

\section{Data collection process}

The data used in this article were obtained from questionnaires, selfreflection sheets in portfolios, focus groups and diary entries in a research journal. Questionnaires were handed to participants prior to and following training, and were collected by hand after completion. The four participants from each school were required to implement the strategies in the classrooms for a period of at least 3 weeks following the workshops. At the end of the implementation period, they were required to engage in self-reflection (guided reflection) and to include the self-reflection sheets in their portfolios.

The focus groups met within 4 - 6 weeks of the workshop to establish the value of the learning experience and to monitor the implementation of the strategies taught. In addition, diary entries were made throughout the process to reflect on the process. Such diary entries were included as data.

\section{Credibility}

All the qualitative data analysed were reviewed by inter-rater agreement of coding with $80 \%$ accuracy. Focus groups were conducted in both contexts. At the end of each focus group meeting, the assistant moderator verbally summarised the responses to questions (as documented from the completed summary sheet). Member checking was done immediately when these summaries were presented to the group for approval, thereby increasing the trustworthiness of the data. After the participants had departed, the researcher and the assistant moderator met to reflect on the procedures, the participation, and 
outcomes of the session. They compared notes and confirmed the key ideas. The researcher further reflected on the focus group shortly afterwards with entries in the research diary. Thick descriptions within the context were created and rich data from several data sources (diary entries, focus groups, questionnaires and portfolio reflections) were triangulated, which increased the credibility.

\section{Data analyses}

Content analysis (qualitative research) provided a clear description of classroom practices and the experiences of the trainees following the support provided (Leedy \& Ormrod, 2010). The focus group transcriptions, diary entries and open-ended questions from questionnaires were qualitatively analysed with ATLAS-ti (Thomas Muir Scientific Software Development, 2003 - 2004) (qualitative descriptive analysis). Such software allowed for counting of the occurrence of the codes (enumeration) to determine the prominence thereof. Items coded were then grouped as categories and themes within the logic model framework of input, process, output and outcomes. Where the overall project reported previously (Wium, et al., 2010) focused on the process of providing support, this article concentrates on the outcomes of the component that facilitated language skills. In the overall study all items coded were quantitised by using a binary scale to categorise the data as either positive or negative (supporting the item, or refuting it), which allowed a comparison of quantitative and qualitative data within a mixed methods approach. The interpretation of the inferences was subjected to a validation process before final conclusions could be drawn.

\section{Results and discussion}

The binary classification used to interpret the data in the overall project is used in this article as it reflects how the strategies were implemented in the classroom, and the benefits obtained from the support provided. In terms of the former, the following themes can be identified: increased competence in meeting curriculum outcomes, working in themes, and language issues. The benefits of the CPD programme are discussed in terms of the benefits to the teachers (e.g. improvement in lesson planning, working in a theme and language issues), and for the learners (e.g. increased participation of all learners, and enjoyment). Selected extracts and quotes obtained from the qualitative data are provided in italics in the discussion of the results.

\section{Implementation of strategies in the classroom Meeting curriculum outcomes}

The benefits obtained from the support by the teachers included an increased ability to address the curriculum outcomes through the implementation of specific strategies. Perceptions of increased competence with the implementation of strategies to facilitate language learning became evident from the following quotes:

'I took many things out of that story. I made a song, made a poem, and then they must do the plurals, the opposites, segmentation, and then I also stated the new vocabulary. It takes maybe two weeks ... on one story. Which is [why] I forgot about the assessment.' (Line 28, focus group 1)

'That any story can teach learners all the learning outcomes.' (Line 20, reflection and self-evaluation of teachers)

The use of stories allowed the participants to integrate various assessment standards within a single activity, which is in accordance with the principles of OBE. The support also integrated literacy with other learning areas, e.g. life skills, where values such as respect for animals could be taught.

'A told us how much the story has made an impact on her class. Previously she taught numeracy through counting (rote counting). Now she makes sure that the story introduces the numbers and concepts within a more meaningful manner (Line 22, diary entry 18, pilot focus 2)

T: 'When we tell the story, animals (some learners do not respect animals), when I tell them about animals; they see that they have to respect the animals.'
F: 'Was that because of the story or why did they learn to respect animals?'

T: 'The story that I was telling - they have changed. I think they have changed.' (Line 42, pilot focus group)

In both contexts it became evident during role-play activities conducted in the workshops that some participants at first did not clearly understand how to construct a story or how to hold the attention of learners when reading a storybook. This may be because either they have not used this strategy before, or possibly because having to use English (which was an additional language for all participants) in the role play activity, which could have inhibited their ability to express themselves freely. In general, the participants reported that the use of a story with pictures, as well as book reading, yield satisfactory results as their learners were able to listen attentively and to retell the story. The inference is that the implementation of the story and the use of pictures enhanced the learners' receptive and expressive language skills.

T: And even that one of ... the sequencing. When I was just telling them the story, so that they listen and then afterwards, they could tell the story. They were able to sit and listen and then afterwards they could tell us the sequence.' (Line 46, focus group 1)

\section{Support in lesson planning}

Support in lesson planning had particular value to the participants. Prior to the support provided, many of the participants did not understand the value of integrating various activities around a central theme in order to enrich the learners' conceptual language base and understanding of vocabulary. The participants agreed that using a central theme helped them to plan their lessons.

T1 'Yes it helped me with planning of the lesson.' (Line 191, focus group $3(b))$

T2: 'Most of our teachers had problems with planning our lessons. Or creating LOs. I am so perfect now. I can now use the one LO and apply it to another - we kill two LOs.' (Line 284, pilot focus group 1)

Strategies to be used within a central theme, e.g. stories and role play, relate to the functional approach to language learning and increase linguistic awareness (Owens, 2004).

\section{Working within a central theme}

In general the songs and nursery rhymes supported and expanded vocabulary pertaining to the original theme of the story, and highlighted semantic and syntactic forms (Paul, 2007). Songs and rhymes supported by transparent gestures or accompanied by movements, as well as role play, allowed for repetition of vocabulary, but also provided the opportunity for multimodal experiences that could facilitate learning. Such strategies provided a 'script' for learning language, as learners were encouraged to fill in parts that have purposefully been left out once the learners have become familiarised with the story, song, or rhyme.

'I was thinking that if all the teachers were attending workshops like these, lots of things were going to change at our schools - involving the negative attitudes of teachers for learners who have barriers, and teachers themselves who don't realise that they are barriers themselves for the learners. Because they don't want to apply new strategies in their lessons.' (refer to HU 46, line 33. Testimonials of learner support teachers)

A few participants complained that they found it difficult to match the story with a rhyme and/or a song within a specific theme.

They complained about how difficult it had been to design a good story that encompassed all the different elements stipulated in the assignment. (Line 17 in diary entry 18, focus group 2) 
It is possible that the participants had followed a fragmented approach in the past where such activities were conducted in isolation, as was the case with the previous transmission approach to learning. In this case these participants may have benefited from more peer support or mentoring.

A central theme was instrumental in the creation of a meaningful context that facilitated understanding and allowed for the use of a variation of intervention activities. Themes allowed the learners in class to incorporate new learning into existing frameworks and to gain familiarity with concepts (allowing them to express these in language), as well as to develop understanding. Apart from providing activities for listening and speaking, teachers were required to encourage reading and writing within the general theme of the week. The use of a theme integrated the thread of language throughout the curriculum in all classroom activities. Such activities within specific themes allowed for cultural diversity and various learning styles, and therefore created an optimal learning environment for learners.

\section{Language issues}

Some of the participants reported that the use of prepositions was difficult to implement when the LoLT was an African language. They explained how they made use of different ways to express the use of prepositions.

T: 'I also struggled, so I looked at the story and tried to implement the strategies. But some of the things we do not do in N Sotho. Like... prepositions, and ... adjectives!' (Line 97, focus group 2)

\section{T: 'We say Ka-ga-re (inside), kamorago (behind). E-kamogare.} E-mogauswe, E-kamorage (sing-song style).' (Line 109, focus group 2)

These participants tended to use archiforms (e.g. use of one member of a word class to represent all members) to refer to several positions in space and augmented the meaning with different hand gestures. Such use of prepositions relates to the typical language use of additional language speakers, although in this case archiforms were used by some of the participants when communicating with learners in their L1.

Some participants reported on their learners' limited vocabulary, which did not include a wide range of prepositions, and that learners often use a single preposition to represent several others. They reported that they refer to positions in space in a similar manner as their learners do, because they do not expect their learners to understand them if they express themselves differently. Such practices did not allow for conceptual growth or for an expansion of vocabulary and therefore these participants' lack of insight and/or limited proficiency in the LoLT could be regarded as barriers to learning. The importance of language modelling (Paul, 2007) needs to be emphasised in future programmes because learners need an adult as 'knowledgeable other' (in this case the teacher) to provide them with the relevant insights within cultural and social exchange. It should be noted that these teachers' limited insight into what language consists of and how it can be facilitated can be attributed to several reasons which are rooted in the South African context (e.g. inadequate prior training of teachers who were trained under the previous dispensation, and the lack of formal qualifications).

Increased insight in meta-language was noted as some participants also complained that subject-specific vocabulary and terminology do not necessarily exist in indigenous languages, which required of them to explain such concepts through the use of gestures, or by making use of more elaborate descriptions.

\section{F: 'But then you explain it with gestures? You can also explain "kagare" as being "behind"?' (Line 109, focus group 2)}

\section{Benefits of the programme}

The inferences indicated that $95 \%(n=288)$ of all items coded in terms of the benefits of the programme were positive, but these results are discussed separately as benefits to the participants and the learners.

\section{Benefits of the CPD programme to the participants}

The results indicated that $96 \%$ of the 137 items coded were positive; this included the participants' perception of changes that occurred in their teaching practices, and their ability to reflect on their practices, as well as their empowerment.

'It has empowered me enormously and I am highly skilled to deal with learners' problems with sound-right strategies, and confident to approach any learning problem and to assist my colleagues with pride.' (Line 128, un-tabled open questions, forms 2 \& 3)

Evidence of 'empowerment' ( $n=17$ ) is related to the fourth of five levels of knowledge acquisition described by Miller \& Watts (1990), where learners become knowledgeable to the extent of training their peers. In this case, it resulted in some of the participants training their colleagues (and was therefore coded as 'training of others'). Coenders, Terlouw and Dijkstra (2008) reported on the successful preparation of teachers for a new science curriculum by having them develop and use curriculum materials, as it created ownership and strengthened their pedagogical content knowledge (PCK). Even though a small sample ( $n=7)$ was used in their study, these findings resonate with findings in this study where teachers had to prepare lesson plans for assessment.

Moreover, as the participants came to realise that they all shared similar problems, a network of support was established between schools.

They also came to realise that others are in the same boat, and that they need to support one another as teachers. Networking was also established (Line 42, diary entry 25).

A sense of collegiality appeared to have developed between the participants through sharing experiences, which verifies the value of group and peer learning.

\section{Benefit to the learners}

The effect of the programme on the learners is described by information obtained from secondary data on participants' perceptions of the effect of the strategies on their learners. In general the participants were positive $(94 \%, n=132)$ about the effect the strategies had on their learners, which is promising as Gilmore and Vance (2007) found a positive correlation between teachers' overall rating of attentive listening and learners' verbal comprehension test scores.

Research to determine the impact of programmes on learners' performance is limited. The current study reported perceived gains made by learners, but these findings were subjective. The effect of CPD programmes on learners' performance needs further investigation.

\section{Increased participation of all learners}

All the participants $(100 \%, n=34)$ testified to the increased 'participation of the learners' when using the newly acquired strategies and activities, especially from learners who had been excluded in the past or would not participate. They particularly reported how learners participated in songs and listened to, and retold the stories.

'Learners can tell the stories with the pictures. Even the learners who struggle, they can tell the story.' (Line 35, focus group 1)

The learners were all able to retell the story and to participate in the songs using gestures and actions. Such participation in these activities allowed learners to sufficiently internalise the language to eventually participate through the verbal medium.

\section{Enjoyment of lessons}

A particular attribute of the programme was the element of 'enjoyment' that was experienced $(100 \%, n=19)$ across contexts, and is illustrated in Figure 3. Because the learners enjoyed the new activities and participated in the classroom, the participants (teachers) responded positively and expressed their excitement about the outcomes. Enjoyment of learning experiences facilitated learning in both the learners and the participants. 
'These strategies provide the language development. The classes are so much fun ... sometimes I look at my class and I cannot believe the difference. The children, they all enjoy the lessons so much. Sometimes I feel as if I just want to cry.' (Line 46, diary entry 16 on focus group 1)

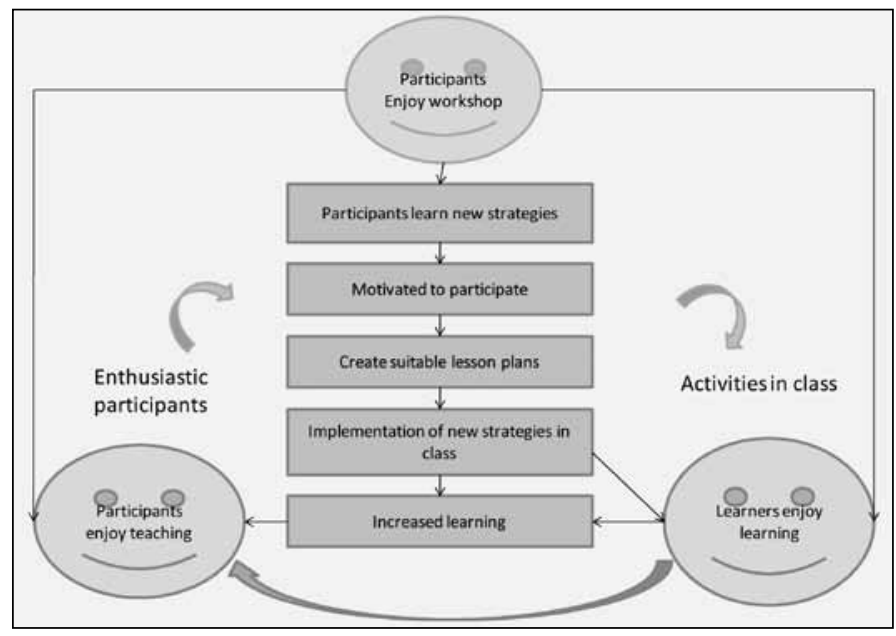

Fig. 3. The role of enjoyment in the programme.

The continued reflection by both the participants and the researcher on the entire process led to their professional and personal growth.

The results indicated that the strategies for language facilitation were experienced as positive ( $83 \%$ of the items coded, $n=18$ ). A summary of the results with regard to the implementation of the strategies and the benefits of the support provided are summarised in Table II.

\section{Table II. Summary of the results obtained in the outcomes component}

\begin{tabular}{ll|}
$\begin{array}{l}\text { Area assessed } \\
\text { Implementation of strategies }\end{array}$ & Results positive \\
Benefits of the programme: & $70 \%(n=125)$ positive \\
Learners & $94 \%(n=132)$ \\
Participants & $96 \%(n=137)$ \\
Enjoyment & $95 \%(n=19)$ \\
\hline
\end{tabular}

\section{Negative findings}

Negative findings were related to the 'process' component of implementing the CPD programme, particularly the use of portfolio assignments with lesson planning, which were met with resistance as it added to the participants' workload and put them under pressure.

T: 'Implementation is very good, the problem is this assignment. To know ... to write it. But it helps us. It really helps us. When we start planning again for those ... or your ... compiling everything. But I don't like the assignment.' (Line 12, focus group 2)

The participants also complained about time constraints in completing the portfolio assignments or implementing the strategies. Such complaints were attributed to busy schedules, high workload, and low intrinsic motivation, which could be related to limited support from the school or a negative school culture.

T: 'Yeah, because of lack of time. We have been so busy.' (Line 303, Focus group 1)

T: 'In the week it is difficult. I think we should work on it for another two weeks.' (Line 161, focus group 1)

T1: 'It has been so hectic, since the schools closing.'

\section{T2: 'Busy, very busy.'}

\section{A-M: 'With what?'}

T: 'With meetings, some of the workshops.' (Line 15, focus group 2)

\section{Sustainability of the CPD programme}

This CPD programme was one example of support provided to teachers and the question remains whether it had any long-term effect as it has not yet been researched. The complex nature of education as a contested context (McMillan \& Schumacher, 2010; Motshekga, 2010) requires a better understanding from SLTs working in the education environment (O'Connor \& Geiger, 2009). Informal feedback received from the district facilitators 2 years after their training suggested that the lesson-planning format, where groups of grade-level teachers planned their lessons together around a central theme, was still practised in some of the schools, possibly because an integrated thematic approach is supported by the GDE as it is part of an OBE approach. Once, when working in a different context from the research, the programme facilitator encountered members of learner support teams (LSTs) (who did not attend the original workshops), using the workshop handout as a resource, which indicated that the strategies and materials were discussed and shared with other colleagues. The message has spread to a wider community, which had been the original intention from the start, but this could also cause problems and be limiting. An initial introduction to the facilitation of language by means of a workshop, as well as follow-up support, is required to ensure quality and generalisation of principles. Teacher development is not a 'quick fix' for existing problems, but is an ongoing process over time. Information and skills need to be repeated and reflected on continually to bring about behaviour change. Each learning experience provides a scaffold for future learning. While this CPD programme yielded positive benefits the long-term outcomes remain unknown.

\section{Limitations of the research}

In terms of data collection, high levels of non-response were evident in the open-ended questions in the questionnaires, as well as in the critical reflections included in the portfolio assessments. Training venues more central to the schools could have limited late arrivals and subsequent non-response in questionnaires. Factors such as participants not being familiar with reflective practices, limited language proficiency in English, literacy levels, timing and logistics could have contributed to non-response in portfolio assessment. In some instances a negative school culture impacted on the participants' motivation to complete the portfolio assignments.

It is further acknowledged that working in close proximity with teachers over a prolonged period of time could have increased the possibility of over-involvement and subjectivity. The focus group meetings were conducted, transcribed, coded, and analysed by the course facilitator (also the researcher), which could have increased the possibility of subjectivity in the interpretation of results, despite several measures taken to prevent this.

Because the participants were not a homogeneous group (in terms of qualifications, literacy levels, prior knowledge, age, and language proficiency), it is possible that the pace of training was too fast for some, while appropriate for others. These factors also impacted on the completion of questionnaires and portfolio assignments.

As the workshop material was prepared mainly in English, the participants were required to transfer their knowledge to the LoLT, which hampered optimal learning. More examples are required in the LoLT. District facilitators who are proficient in the LoLT need to become more actively involved in the preparation of the workshop material, and need to be trained as co-trainers to bridge the language divide. It is also possible that less information provided in the workshops would have allowed more time for review, which could have 
increased the effectiveness of the training. As research informs practice, the limitations of the research also provide indicators for practice.

\section{Indicators for the practices of SLTs}

- $\quad$ Since it is not practically possible for a single SLT to effectively support every teacher in an entire district, it is essential for SLTs and district facilitators to collaborate. District facilitators are required by the GDE to support teachers in the implementation of the curriculum. They are responsible for the daily support of teachers and therefore need to be supported in their efforts to provide ongoing in-service training in literacy-related skills.

- In a consultative and collaborative capacity, the SLT can provide advice and support with CPD activities related to listening and language facilitation on an ongoing basis. In a collaborative model of support SLTs need to provide staff development activities to increase theoretical content knowledge and skills (King, Strachan, Tucker, Duwyn, Desserud, \& Shillington, 2009) as basis for pedagogical content knowledge. In turn, district facilitators are often proficient in the LoLT and can contribute to the support process by using code switching to bridge the current language divide in workshops for teachers where SLTs are from a different language background. Such a collaborative support programme needs to be developed as action research (Burton \& Bartlett, 2005; Onwuegbuzie \& Dickinson, 2007) as it will have to be adjusted over time to accommodate various topics and be tailor-made for specific contexts.

- A once-off workshop by itself may be useful to introduce new ideas, but its effect is temporary (Massel and Goertz in Roberts, 2002). A 'cluster model' of support as an alternative to large-group support may be more effective. The results of this study indicated that the participants preferred group learning and discussing issues and experiences in small groups while sitting around a table. Group learning (cluster model) may be a more suitable support model for these particular contexts (Killen, 2007). In an attempt to establish a balance between quantity and quality in training, the questions that need to be answered are whether cluster support contributes significantly more to the competence of teachers than large-group workshops and whether it warrants the costs. The advantages and disadvantages of such a cluster model (where small groups will be trained in short sessions over an extended period) as opposed to 'once-off' large-group training should be investigated. The effect of such small-group support could be determined by means of a case study design where both quantitative and qualitative methods are employed (Roulstone, Owen, \& French, 2005).

- Reflective practices are inherent to the OBE approach, but have not yet become familiar practice and need to be addressed in future programmes. Dunst and Trivette (2009) developed the participatory adult learning strategy (PALS) which included 'trainer-guided reflection' to promote child literacy, communication and language learning practices to parents and SLTs, which could be further explored for use with teachers. Continual reflection on their practices, together with practical experiences, will provide the basis for more effective professional growth for teachers and therapists.

- The teachers in this study expressed a need for the SLT (course facilitator) to observe their teaching and to provide individual feedback, which was beyond the scope of the research. In school-based support, the SLTs may want to support teachers through co-teaching and constructive feedback. However, effective collaboration requires that both parties understand their individual roles, and that SLTs take account of the educational environment. Collaboration between SLTs and teachers cannot be taken for granted when these two professions are brought together as they stem from different disciplinary specialisation and knowledge bases. Allen (in Forbes, 2008: 153) is of the opinion that 'Collaboration with other professionals is a complex knot of relationships which has to be learned and worked at. It cannot be assumed that by issuing an enjoinder to collaborate, and by placing people together, that the outcomes will be positive.'

It is necessary to identify each discipline's individual knowledge base and approaches, as well as the new knowledge, skills and approaches required to work together in supporting young learners in South African classrooms. With literacy and numeracy as central focus, the unique contribution of each profession needs to be determined in order to facilitate collaboration in schools. Forbes (2008: 141) based a similar line of enquiry on the 'analytic modes of knowledge' described by Gibbon, Limoges, Nowotny, Schwartzman, Scott, \& Trow (1994), which appears potentially useful as a starting point. However, more contextually relevant information is required for the South African context.

\section{Conclusion}

The results showed that the provision of $\mathrm{CPD}$ activities regarding language learning can be effective as the majority of the participants implemented the strategies in class and valued the new skills acquired. Teachers, as well as learners, reportedly enjoyed the strategies and learnt from them. In view of the relationship between language and literacy, it is imperative that teachers and SLTs work as a team towards a common goal of supporting learners in learning. As team members they need to show mutual respect and show an ability to work towards similar outcomes (O'Toole \& Kirkpatrick, 2007). The results show that the support of teachers is beneficial for both teaching and learning, and that SLTs have an important role to play in the process.

Acknowledgement. The authors wish to acknowledge the support of the Shuttleworth Foundation for supporting the fieldwork.

\section{References}

ASHA (2001). Roles and responsibilities of speech-language pathologists with respect to reading and writing in children and adolescents (guidelines). Rockville, MD: ASHA.

Burton, D., \& Bartlett, S. (2005). Practitioner research for teachers. London: Paul Chapman Publishing.

Coenders, F., Terlouw, C., \& Dijkstra, S. (2008). Assessing teachers' beliefs to facilitate the transition to a new chemistry curriculum: what do teachers want? Journal of Science Teacher Education, 19(4), 317-335.

Department of Education (2001). White Paper 6: Special needs education - building an inclusive education and training system. Retrieved from http://www.polity.org.za/govdocs/white_papers/educ6.html.

Department of Education (2002). Revised National Curriculum Statement for Schools: Grades R - 9. Pretoria Department of Education.

Department of Education (2008). National strategy on screening, identification, assessment and support. Pretoria: Department of Education.

Dunst, C.J., \& Trivette, C.M. (2009). Let's be PALS: an evidence-based approach to professional development. Infants and Young Children, 22(3), 164-176.

Forbes, J. (2008). Knowledge transformations: examining the knowledge needed in teacher and speech and language therapist co-work. Educational Review, 60(2), 141-154.

Gibbon, M., Limoges, C., Nowotny, H., Schwartzman, S., Scott, P., \& Trow, M. (1994). The new production of knowledge. London: Sage Publications.

Gilmore, J., \& Vance, M. (2007). Teacher ratings of children's listening difficulties Child Language Teaching and Therapy, 23(2), 133-156.

Girolametto, L., Weitzman, E., Lefebvre, P., \& Greenberg, J. (2007). The effects of in-service education to promote emergent literacy in child care centres: a feasibility study. Language, Speech, and Hearing Services in Schools, 38, 72-83.

Johnson, K.L., \& Roseman, B.A. (2003). The source for phonological awareness. East Moline, IL: Lingu Systems.

Justice, L.M., \& Ezell, H. (2002). Use of storybook reading to increase print awareness in at-risk children. American Journal of Speech-Language Pathology, 11, 17-29.

Justice, L.M., \& Ezell, H.K. (2001). Written language awareness in preschool children from low income households: a descriptive analysis. Communication Disorders Quarterly, 22, 123-134.

Justice, L.M., \& Kaderavek, J.N. (2004). Embedded-explicit emergent literacy intervention: background and description of approach. Language, Speech, and Hearing Services in Schools, 35, 201-212.

Justice, L.M., Skibbe, L., \& Ezell, H. (2006). Using print referencing to promote written language awareness In T.A. Ukrainetz (Ed.), Contextualized language intervention: scaffolding pre K-12 literacy achievemen (pp. 389-428). Eau Claire, WI: Thinking Publications.

Killen, R. (2007). Teaching strategies for outcomes-based education (2nd ed.). Cape Town: Juta.

King, G., Strachan, D., Tucker, M., Duwyn, B., Desserud, S., \& Shillington, M. (2009). The application of a trans-disciplinary model for early intervention services. Infants and Young Children, 22(3), 211-223.

Leedy, P.D., \& Ormrod, J.E. (2010). Practical research (9th ed.). Boston: Pearson.

Lessing, A., \& De Wit, M.W. (2008, 30 September-1 October). Do teachers know what the essential literacy skills are? Paper presented at the Laying Solid Foundations for Learning meeting, Makopane, Limpopo.

Locke, A., Ginsborg, J., \& Peers, I. (2002). Development and disadvantage: implications for the early years and beyond. International Journal of Language and Communication Disorders, 37, 3-15.

McMillan, J.H., \& Schumacher, S. (2010). Research in education: Evidence-based inquiry. Boston: Pearson.

Miller, A., \& Watts, P. (1990). Planning and managing effective professional development. Harlow, Essex, UK: Longman.

Ministry of Education (2001). National plan for higher education. Pretoria: Department of Education.

Motshekga, A. (2010, 6 July 2010). Statement by the Minister of Basic Education, Mrs Angie Motshekga, MP, on the progress of the review of National Curriculum Statement. Retrieved on 17 August 2011 from http://www.education.gov.za. 
Nancollis, A., Lawrie, B.A., \& Dodd, B. (2005). Phonological awareness intervention and the acquisition of literacy skills in children from deprived social backgrounds. Language, Speech, and Hearing Services in Schools, 36, 325-335.

O'Connor, J., \& Geiger, M. (2009). Challenges facing primary school educators of English second (or other) language learners in the Western Cape. South African Journal of Education, 29, 253-269.

O'Toole, C., \& Kirkpatrick, V. (2007). Building collaboration between professionals in health and education through interdisciplinary training. Child Language Teaching and Therapy, 23(3), 325-352.

Onwuegbuzie, A.J., \& Dickinson, W.B. (2007). Mixed methods research and action research: a framework for the development of pre-service and in-service teachers. Academic exchange. Retrieved on 20 December 2008 from http://asstudents.unco.edu/students/AE-Extra/2007/6/indxmain.html.

Owens, R.E. (2004). Language disorders: a functional approach to assessment. Boston, MA: Allyn \& Bacon Paul, R. (2007). Language disorders: from infancy through to adolescence (3rd ed.). St. Louis, MO: Mosby.

Rembe, S.W. (2005). The politics of transformation in South Africa: an evaluation of education policies and their implementation with particular reference to the Eastern Cape Province. Grahamstown: Rhodes University.

Roberts, J. (2002). District development: the new hope for educational reform. Johannesburg: Joint Education Trust.

Roulstone, S., Owen, R., \& French, L. (2005). Speech and language therapy and the Knowles Edge Standards Fund Project: an evaluation of the service provided to a cluster of primary schools. British Journal of Special Education, 32(2), 78-85.

Stringer, E.T. (2007). Action Research (3rd ed.). Los Angeles, CA: Sage.

Thomas Muir Scientific Software Development (2003-2004). ATLAS-ti: The knowledge workbench V5.0. Berlin, Germany: Thomas Muir Scientific Software Development.

Wium, A.M. (2010). The development of a support programme for foundation phase teachers to facilitate listening and language for numeracy. Pretoria: University of Pretoria.

Wium, A.M., Louw, B., \& Eloff, I. (2010). Speech-language therapists supporting foundation phase teachers with literacy and numeracy in a rural and township context. South African Journal of Communication Disorders, 57(1), 14-22.

\section{Appendix A. Workshop to facilitate language}

The training component of the CPD programme addressed the following topics:

- What is language? As introduction to the CPD programme an explanation of language and why it is important was provided. There was a brief discussion on the aspects and the elements of language, and how it can be facilitated through the use of a variety of relevant activities and strategies (Owens, 2004).

- A balanced approach to facilitating reading and writing. Current evidence (Justice \& Kaderavek, 2004) regarding the acquisition of literacy skills suggests a balance of both contextualised and decontextualised (discrete) skill intervention as best practice. This specific programme supported a 'balanced approach' to the facilitation of literacy (Justice \& Kaderavek, 2004), which creates opportunities to develop an understanding of the language and then uses this understanding as the basis to teach discrete skills within a phonics-oriented, code-based approach (Justice, et al., 2006). Such a balanced approach to literacy encompasses both the 'top-down' (whole language) and 'bottom-up' (phonetic) approaches and is most appropriate in the foundation phase where the focus is on facilitating literacy. The teachers were shown how language develops along a continuum, from oral language learnt in the home through concrete operations, to the decontextualised language required for written language used in school. In order to facilitate language and literacy skills teachers need to be aware of a balanced approach to facilitating reading and writing, and how to use central themes to facilitate the four language systems (listening, speaking, reading and writing) in an integrated manner.

- The use of a theme in integrating the four language systems: The training component of the CPD programme made use of group activities where the teachers planned the use of songs, rhymes, and craft activities, together with listening, reading and writing exercises within a central theme. Such an integrated thematic approach (ITA) created several language-rich experiences and allowed the learners to not only develop the vocabulary related to a specific topic, but to integrate skills across the curriculum (Department of Education, 2002). 